The original publication is available at www.springerlink.com.

Abraham, R., Aier, S.: Architectural Coordination of Transformation: Implications from Game Theory. In: Rahman, H., Mesquita, A., Ramos, I., Pernici, B. (Eds.): Proceedings of the 7th Mediterranean Conference on Information Systems (MCIS 2012), Guimaraes, Portugal. Lecture Notes in Business Information Processing, Vol. 129. Springer, Berlin Heidelberg, 82—96, (2012).

\title{
Architectural Coordination of Transformation: Implications from Game Theory
}

\author{
Ralf Abraham, Stephan Aier \\ Institute of Information Management, University of St. Gallen, Mueller-Friedberg-Strasse 8, \\ 9000 St. Gallen, Switzerland \\ \{Ralf.Abraham, Stephan.Aier\}@unisg.ch
}

\begin{abstract}
Enterprise Architecture Management (EAM) is considered a means to support coordination in enterprises. However, coordination between heterogeneous stakeholder groups with different interests is a challenging task to achieve. In this paper, we take a game-theoretic perspective on coordination in organizations. We identify three coordination games from literature: (1) Matching game, (2) Battle of the sexes game, and (3) Assurance game. For each game, we then provide an example and discuss which EAM deliverables can be employed to support coordination and which implications for the design of EAM can be derived. From the analysis of coordination games, we derive a proposition outlining further EAM evolution along two paths: as an active decision support discipline, but keeping its focus in the IT domain; or moving out of the IT departments and becoming a strategic decision support discipline for enterprise transformation.
\end{abstract}

Keywords: Game Theory, Coordination, Enterprise Architecture Management

\section{Introduction}

Enterprises face an increasingly complex environment which forces them to undergo radical change, in other words transform themselves $[1,2]$ The causes for such transformation efforts range from business- or IT-driven initiatives inside the enterprise to outside events such as the emergence of new technologies or the introduction of new regulatory requirements. The increasing complexity in the environment leads to an increasing complexity of the enterprises themselves.

Large-scale transformation efforts affect multiple domains and layers within an enterprise [3], performed simultaneously in different projects and programs. Providing coordination in the course of enterprise transformation aims to ensure that the overall 
transformation targets are met, that the enterprise as a whole evolves in a consistent way [4]. The rationale behind this is that an approach focusing solely on local optimization within projects, without having an overarching coordination mechanism, will not necessarily lead to - or in the worst case even hamper - the development of the enterprise in the intended direction.

A discipline that has been proposed to support the coordination of enterprise transformation is Enterprise Architecture Management (EAM) [4, 5, 6]. Descriptively, EAM provides a high-level blueprint of an enterprise, addressing both business and information technology (IT) aspects and particularly the interdependencies between them [7]. Prescriptively, it provides principles and guidelines governing an enterprise's evolution [8]. However, EAM is currently used in very different ways by enterprises, with its impact more often than not limited to a documentation function for the IT domain [9]. Analysts company Gartner predicts that the IT "home grown star" EAM will and has to be moved outside IT departments in order to deliver on its promise and actually evolve towards an enterprise-wide decision support discipline, either as a discipline by itself or its practices becoming integrated into both business and IT strategy [10].

Since organizational transformation is concerned with fundamental change covering many facets of an enterprise, it involves and affects a large number of stakeholders with heterogeneous concerns, organizational tasks and individual interests. Therefore, it is essential to understand individual stakeholder's preferences and the potential conflicts that may arise between them in the course of transformation. However, this is seen as one of the current shortcomings with EAM [11].

In an organizational context, stakeholders are mutually dependent on each other's actions: To achieve an organizational goal, each stakeholder has to choose a particular action. The organizational goal, e.g. the intended transformation result, is reached only if all involved stakeholders choose the appropriate action, i.e. if they coordinate on cooperative behavior. However, stakeholders' individual goals may agree or conflict with organizational goals and may also be influenced by the actions of their peers: For example, a group of line managers may want to choose a particular action only if they believe their peers will do the same.

A way to describe coordination situations between stakeholders, while particularly taking into account stakeholders' actions mutually influencing each other in an organizational context, is provided by game theory. Next to its formal description of the behavior of players, a main contribution of game theory is providing a classification system for decision situations between people [12]. By describing coordination situations in terms of games played between players and analyzing the different payoff matrices, requirements for coordination support in different scenarios may be deducted. Based on these requirements, the possible contributions on EAM in these situations can be delineated.

Our research questions are the following:

1. Which requirements must be met by EAM in each coordination situation?

2. What are the implications for the design of EAM in each coordination situation? 
The remainder of this paper is organized as follows. In the next section, we will provide foundations of game theory and game-theoretic representations of common coordination problems based on organizational literature. Section 3 gives a brief overview on EAM and shows requirements and possible contributions in each coordination game. Section 4 discusses our findings and points out possible EAM evolution paths. The paper ends with a summary section discussing limitations and providing a brief conclusion.

\section{Game Theory and Coordination Games}

Game theory is concerned with the analysis of interactions among rational decision makers. Each player's gain is defined by the combination of his own decision as well as those of other players: his own benefit also depends on the action chosen by the other player. An important function of game theory, next to its formal description of rational players, is providing a classification system of social interactions and decision situations [12]. By doing so, game theory offers a clear language and representation form to describe and compare social interaction between rational participants.

The assumption of rationality has often been criticized: people usually do not behave in a purely rational fashion, but often base their decisions on emotions or instincts as well. Rationality alone cannot fully explain or predict an individual's decisions. However, in groups and in reoccurring situations, as is the case in an enterprise setting, people tend to move towards rational decision making [12]. Therefore, game theory is considered a useful approach in describing organizational coordination situations $[13,14]$.

For the purpose of this paper, two concepts from game theory are central: Nash equilibrium (NE) and Pareto efficiency. A NE is reached when no player can realize a higher gain by unilaterally deviating from a set of chosen strategies. It is a set of mutual best responses - no rational player has an incentive to change his strategy under the condition that the other player sticks with his strategy.

Another important concept for the analysis of coordination needs is Pareto efficiency. In a Pareto efficient solution, no player can increase his utility without decreasing the other player's utility. Contrarily, in a Pareto inefficient solution, both participants could be better off. While a NE constitutes an individual optimum, a Pareto efficient solution constitutes a social optimum.

To further illustrate the two concepts, consider the classic prisoner's dilemma game. It describes a game between two criminals accused of a particular crime, who are both questioned separately and therefore have to make independent decisions: From each combination of decisions, a different sentence arises for the individual player. The respective payoff matrix is given in Fig. 1 . 


\begin{tabular}{|c|c|c|c|}
\hline Cooperate & $\begin{array}{l}\text { Cooperate } \\
(2,2)^{*}\end{array}$ & $\begin{array}{l}\text { Defect } \\
(0,3)\end{array}$ & $\begin{array}{l}\text { Note: NE are } \\
\text { marked in grey, an } \\
\text { asterisk }(*) \text { denotes }\end{array}$ \\
\hline Defect & $(3,0)$ & $(1,1)$ & Pareto efficiency \\
\hline
\end{tabular}

Fig. 1. Payoff matrix for the prisoner's dilemma

Both players confessing the crime (defecting) results in each player receiving a longer prison sentence than both players denying the crime (cooperating). Hence both players' payoff for cooperating $(2,2)$ is higher than their payoff for defecting $(1,1)$. However, if one player betrays the other by defecting (e.g., turning state's evidence), he receives an even higher payoff (walking free: payoff of 3) at the expense of the other player who receives an even lower payoff (getting the maximum sentence: payoff of 0 ). These two options are given as $(3,0)$ or $(0,3)$, depending on the row or column player's perspective.

From Fig. 1, the essence of the prisoner's dilemma can be seen: Both a NE and a Pareto-efficient solution exist, but they result from different strategy combinations: Both players cooperating would be Pareto efficient, but the NE purely rational players will converge upon is both players defecting.

Camerer and Knez [14] argue that most organizational situations are not prisoner's dilemmas, but games of coordination instead. Their rationale is based on the idea that in organizations, players know each other and play games repeatedly, i.e. over a long period of time. Moreover, players are not forgetful and remember past actions of their peers. Therefore, strong social control exists, and experimental data have shown that players wish to reciprocate nice behavior: they are willing to sacrifice some personal utility to work towards a common goal [15]. In many organizational situations, players can realize a higher benefit by collaborating (whereas in the prisoner's dilemma, the highest individual benefit is achieved by defecting).

Coordination games - unlike the prisoner's dilemma - have multiple pure strategy NE. This property of coordination games in particular is also the rationale for choosing game theory as a theoretic foundation to describe coordination situations in organizations: With multiple NE available, organizations will aim at coordinating players on the Pareto efficient outcome or find a way of balancing if the NE cannot be Pareto ranked.

In the following, a summary of three organizational impediments to coordination and a game-theoretic expression for each of them will be given. The selection of coordination impediments and games is based on Camerer and Knez [14]. Fig. 2 provides the respective payoff matrices. 


\begin{tabular}{llllllllll} 
& Low & High & & Football & Opera & & Hare & Stag \\
Low & $(1,1)$ & $(0,0)$ & Football & $(2,1)^{*}$ & $(0,0)$ & Hare & $(1,1)$ & $(1,0)$ \\
High & $(0,0)$ & $(2,2)^{*}$ & Opera & $(0,0)$ & $(1,2)^{*}$ & Stag & $(0,1)$ & $(2,2)^{*}$ \\
\hline
\end{tabular}

(a) Matching Game

(b) Battle of the sexes Game

(c) Assurance Game

Note: NE are marked in grey, an asterisk $(*)$ denotes Pareto efficiency

Fig. 2. Payoff matrices for the coordination games

The matching game (Fig. 2 a) has two pure strategy NE, with the (High,High) equilibrium Pareto dominating the (Low,Low) equilibrium. The corresponding organizational impediment to coordination is failures in teams. The term "team" is used in organizational literature [16] to characterize a group in which each member has the same preference over the outcome of the game. In this game, there is no conflict of interest, but players still need to exchange information to coordinate on the mutually desired outcome - in particular, they must be aware of the existence of the Paretoefficient (High, High) strategy.

In the battle of the sexes game (Fig. 2 b), there are two pure strategy NE which are both Pareto efficient. No NE Pareto dominates the other since players have different preferences over the outcome of the game, and by changing to the other NE, one player would concede some of his payoffs to his counterpart. The associated impediment to coordination is a bargaining problem, caused by a mixed-motive conflict between players: Every player prefers a different outcome (in the classical game theory example of a couple, one prefers the football match, while the other prefers the opera), but both players prefer giving in to the other's demand to not coordinating at all. In the organizational context, participants prefer finding some solution, but each solution gives one player a higher payoff than the other, due to their different preferences. Players agree, however, that finding no solution is the worst possible outcome.

The assurance or stag hunt game (Fig. 2 c) also has two pure strategy NE with one Pareto dominating the other. It describes a situation where coordinating on the higher outcome is associated with some risk: As in the matching game, the optimum outcome will only materialize if all players do indeed cooperate (which would yield a payoff of 2 by both going for the stag), but in contrast to the matching game, individual players have the option to play a safe strategy which guarantees them a lower payoff (going for the hare guarantees a payoff of 1). The associated organizational problem is stakeholders supporting transformation (e.g. by making investments in learning new skills or adopting new processes) only if they know and trust other stakeholders to do the same. Stakeholders who do not believe in the common goal or trust their peers to work towards it have the option to stick with the status quo, so they will not have invested "in vain" should the transformation eventually fail.

This situation essentially models a trade-off between individual safety and collective cooperation. Therefore, it is also referred to as a situation of "risky coordination". The game basically breaks down to trust and the convergence of expectations [17]. In 
order to coordinate on the Pareto optimum, players must choose the riskier strategy themselves and must also trust other players to do the same. Whereas the matching game discussed earlier requires participants only to know about the Pareto efficient outcome, the assurance game introduces an additional condition: Players must know that their peers also know about the collectively optimal strategy and, moreover, they must trust each other to work towards it. The main difference to the matching game, as evident when comparing the payoff tables, is that non-coordination offers the individual player a risk-free alternative in the assurance game. Therefore, merely communicating an organizational goal and making sure everybody knows about it as in the matching game is not enough: The goal must be credible enough so that players trust others to risk going for it [17].

\section{Enterprise Architecture Management in coordination games}

This chapter will briefly outline EAM, before discussing its contributions to each of the aforementioned coordination games.

\subsection{Enterprise Architecture Management}

Enterprise Architecture (EA) involves both a descriptive and a prescriptive dimension: In a descriptive sense, EA describes the fundamental structure of an organization by providing a high-level overview on the structure of and dependencies between strategic goals, organizational processes and the underlying software and infrastructure systems. In a prescriptive sense, EA is concerned with establishing guidelines and principles governing an enterprise's evolution by restricting design freedom [8, 18, 19]. This notion of architecture, both representing structure and guiding change, corresponds to the ISO/IEC/IEEE Standard 42010, which defines architecture as "the fundamental organization of a system, embodied in its components, their relationships to each other and the environment, and the principles governing its design and evolution" [20].

In the field of EA, a multitude of methods and frameworks have been developed to address modeling and planning of current and target states of the enterprise [21, 22, 23]. Providing transparent documentation on organizational structure, information flows and implementation of software systems is seen as a key deliverable of EA [7, $24,25]$. Transparency means displaying information in a manner that enables effective decision-taking [26]. This poses a two-fold challenge: on the one hand, supplying complete documentation that covers all relevant aspects (strategy, organization, technology) of an enterprise's current state, yet on the other hand presenting this information to stakeholders with a scope that enables managing this overwhelming amount of information, thus making order out of chaos. Transparency is seen as a key antecedent for EAM to be able to support strategic change [27].

Enterprise Architecture Management (EAM) addresses the establishment and continuous development of EA. It controls the evolution of EA and business change from an architectural perspective. EAM has thus been proposed as a means of coordinating 
enterprise transformation $[4,5,6]$. EAM is driven by business- or IT-related scenarios [28], based on stakeholder goals [29]. However, the variety of stakeholders and their conflicting goals create "wicked problems" [30], i.e. problems that are characterized by confusing formulation and conflicting values of many decision makers.

Consequently, identify conflicting stakeholder needs and perspectives and coordinating between them is seen as one of the current issues with EAM [11]. By providing a game-theoretic perspective on stakeholder motivations and payoffs, this paper aims at better understanding stakeholder behavior and deriving insights for the evolution of EAM.

\subsection{Matching game}

In the matching game, players do not have conflicting interests and are willing to cooperate. However, especially in large enterprises with complex structures, coordination is still far from trivial. Players need to be aware of each other and their options. Organizational examples for such a situation are reuse of software components or business services, or finding the right person in the enterprise for collaborating on a project that is beneficial to all partners. The benefits of the individual players are at the same time the benefits of the enterprise: Increased consistency by reuse of existing functionalities and avoiding duplicate work. The essence in this situation is that improving player's information supply will help steer them towards the Pareto efficient solution.

In order to support this coordination game, EAM must create transparency. The main determinants here are information supply and its visibility. Information supply means providing up-to-date models of the structure and relationships between processes and information systems from a high level perspective. To maintain the quality of the information supply, keeping the documentation models updated in the event of organizational changes and providing an appropriate form of representation is vital. EAM essentially provides a common language for multiple stakeholder groups.

However, both the information supply and visibility aspects need to be further developed: To support enterprise-wide coordination, EAM must address the information needs of a broad variety of stakeholders. EAM predominantly provides models on business processes, software systems and the data flows and interdependencies between them. This information caters for the needs of EAM stakeholders like business and IT departments [31]. However, information needs of other stakeholders are currently not readily provided by EAM. Extending the information supply to financial performance indicators or competence profiles associated with processes, and integrating these with traditional EAM models, may increase the EAM value for a wider number of stakeholders like management accounting or human resource management.

For the visibility aspect, the organizational positioning of a coordination function like EAM is critical. If EAM is deployed inside an IT or business department, appropriate communication measures must be pursued to ensure that all relevant stakeholders are aware of its existence and services. Having EAM deployed on a global level, as a corporate support discipline, will increase its visibility. Consequently, its infor- 
mation supplying capability becomes more likely to be actually noticed and used by stakeholders.

\subsection{Battle of the sexes game}

In contrast to the matching game, players in the battle of the sexes game have different preferences. This is the only of the three games that has two Pareto efficient NE. As a consequence, merely providing transparency will not solve this coordination problem. From an organizational perspective, non-coordination is the most detrimental option that is to be avoided. While the overall payoff for the enterprise is equivalent in both NE, each possible coordination option will offer one player a higher benefit than the other. Eventually, a balancing action needs to be taken.

The conflict between business and IT departments regarding standardization issues is an example of such a coordination problem: While business departments wish to have systems customized to their specific requirements in order to increase operational flexibility, IT departments strive for standardization as a means of controlling costs and complexity [31]. Similarly, Murer et al. [32] describe a trade-off between business value and agility, where a one-sided focus on either objective will eventually lead to hardly maintainable systems on the one hand or solutions that are too inflexible to meet business unit's demands on the other hand. In the long run, a balancing action needs to be taken, for example efforts to reduce the heterogeneity of IT systems if the landscape has become too fragmented. Murer et al [32] refer to this balancing as "managed evolution".

When the battle of the sexes game is played repeatedly, as is the case in an enterprise context, a simple and fair solution would be to alternate between player's objectives: In the classic game theory description of the battle of the sexes game, the couple could take turns in going to the football match or the opera. In the organizational context, a similar balancing function is called for in such battle of the sexes conflicts. However, finding the right moment to carry out the balancing action is a challenging task. Eventually, management is responsible for resolving such conflicts by making deliberate architectural decisions.

Providing transparency on the status quo is an essential requirement in this situation, but it is not sufficient. EAM may support this coordination situation by providing an organizational history in the form of a record of organizational decisions. A sense of predictability and justification may thus be established, eventually increasing stakeholder's acceptance of the decisions taken. This could be implemented by incorporating rationales for decisions in the supply of information. In the conflict between business flexibility and IT standardization, providing organizational history may also help management determine when a re-balancing action is needed. Research has shown that managerial decisions are in fact influenced by organizational history [33]. Aveiro et al. [34] also argue for organizations to be aware of their past decisions in order to guide future changes.

Since EAM is to provide decision support in this situation, it should be positioned accordingly in the organization $[26,35]$, i.e. reporting to management and not be located in the line organization. This currently poses a problem for EAM approaches 
that are deeply rooted in the IT departments and have little impact beyond [9]. However, in practice a small number of cases can be observed where an EAM function for exactly this reason is located outside the IT department, reporting to the chief operating officer, for example. In this situation, EAM may ultimately support coordination and balancing over time.

\subsection{Assurance game}

Like in the matching game, there is only one Pareto efficient NE, so organizations have a target to coordinate upon. However, the key difference in the assurance game is the issue of trust: Players unwilling to take a risk in trusting other players to work towards global goals as well will prefer a locally optimized, safe solution [36].

An organizational example is the introduction of an enterprise-wide artifact, like a planning or review process for business unit projects or an integration platform covering or replacing various individual software systems. Such artifacts - if widely adopted - may provide synergies for the enterprise as a whole as well as for the individual business units by reducing heterogeneity and redundancy. A concrete case might be a superordinate planning and review process covering individual business unit's project proposals, to avoid the provision of parallel systems (for example, each business unit developing and maintaining its own time management system).

In contrast to the battle of the sexes game, where motivation is intrinsically different and players see no greater benefit giving up their own preference and coordinating on the global goal, players in this situation are aware of potential long term benefits. However, they also see a loss of individual autonomy associated with supporting the globally optimum solution. Players see the benefit only materialize if a critical mass of their peers cooperates as well. Thus, the willingness to cooperate for each player depends on his perception of the overall cooperation rate. Players who do not wish to cooperate may instead play the safe alternative of sticking with the status quo; but the enterprise pays the long-term price by not moving to the Pareto efficient solution.

Basically, coordination in this situation may be fostered by either incentives or sanctions: Cooperating business units or early adopters may be financially rewarded, and success stories may be communicated in order to create a bandwagon effect. On the other hand, strong principles and guidelines may be employed to mandate adoption of the new solution. This alternative, however, requires strong governance structures as well in order to actually enforce compliance [37]. In practice, a mix of both alternatives is likely to take place, e.g. providing incentives while at the same time making players aware of the existence of sanctions. The eventual mix is dependent on various contingency factors like existing governance structures or organizational culture.

In either case, displaying top management awareness and support in a credible way is essential in this coordination game [17]. To support the sanctioning alternative, EAM can provide architectural principles and guidelines (e.g., granting exceptions only when participants give convincing rationales or requiring payment of a price premium for sticking with the old solution). To support the incentive alternative, EAM can provide transparency on the status quo, a history of organizational decisions 
(including rationales for these decisions) and success stories: Communicating success stories to a wide audience and making stakeholders' commitments transparent to each other may give players the motivation to coordinate on the Pareto optimum outcome. An important factor here is mutual trust. Pirson and Malhotra [38] suggest that for stakeholders with deep, internal relationships to the organization, i.e. employees, transparency is a significant predictor of trust. EAM deliverables related to transparency like up-to-date documentation, as well as a record of organizational history can therefore support coordination in this game by fostering trust. However, they are just one component in coordinating such a situation, next to organizational culture and communication.

Credibility of management interventions is a key requirement here to make stakeholders' expectations converge [17]. In order to support this coordination situation, EAM should not have an IT-centered focus (and possibly bias), but be perceived as a corporate function. Ultimately, if organizations manage to decrease the payoff of the safe solution by either providing incentives or sanctions, the assurance game may be turned into a matching game. Here, the Pareto efficient outcome can be coordinated upon more easily.

\section{Discussion}

EAM can support coordination in both a passive and an active way. In the passive way, its function is creating transparency by providing documentation on the structure of the enterprise's business processes and underlying IT infrastructure. In the active way, EAM serves as a decision support function and helps management address the battle of the sexes and assurance game. Table 1 provides a summary of the findings for EAM in respect to each coordination game.

Table 1. Requirements for EAM from coordination games

\begin{tabular}{llll}
\hline & Matching game & $\begin{array}{l}\text { Battle of the } \\
\text { sexes game }\end{array}$ & Assurance game \\
\hline EAM & $\bullet$ Documentation & $\bullet$ Leadership & $\bullet$ Leadership support \\
Function & & support & $\bullet$ Building trust \\
& & Balancing & \\
\hline EAM & $\bullet$ Transparency & $\bullet$ Transparency & $\bullet$ Transparency \\
Deliverables & & $\bullet$ History and & $\bullet$ Guidelines \\
& & rationales of or- & $\bullet$ History and rationales \\
& & ganizational de- & of organizational deci- \\
& & cisions & sions \\
\hline EAM Design & $\bullet$ IT-centered EAM & $\bullet$ Developing & $\bullet$ Developing EAM into \\
Implication & still possible, howev- & EAM into a de- & a decision support \\
& & &
\end{tabular}




\begin{tabular}{lll}
\hline er stakeholder aware- & cision support & function for manage- \\
ness is critical & function for & ment \\
- Suitable form of & management & $\bullet$ Only feasible with a \\
representation for & & high EAM maturity, i.e. \\
stakeholders outside & & a "track record" \\
IT is necessary & & \\
\hline
\end{tabular}

Our analysis of the coordination games yields two important dimensions for the development of EAM into a coordination support for enterprise transformations. Fig. 3 depicts these two dimensions and evolution paths of EAM within each dimension.

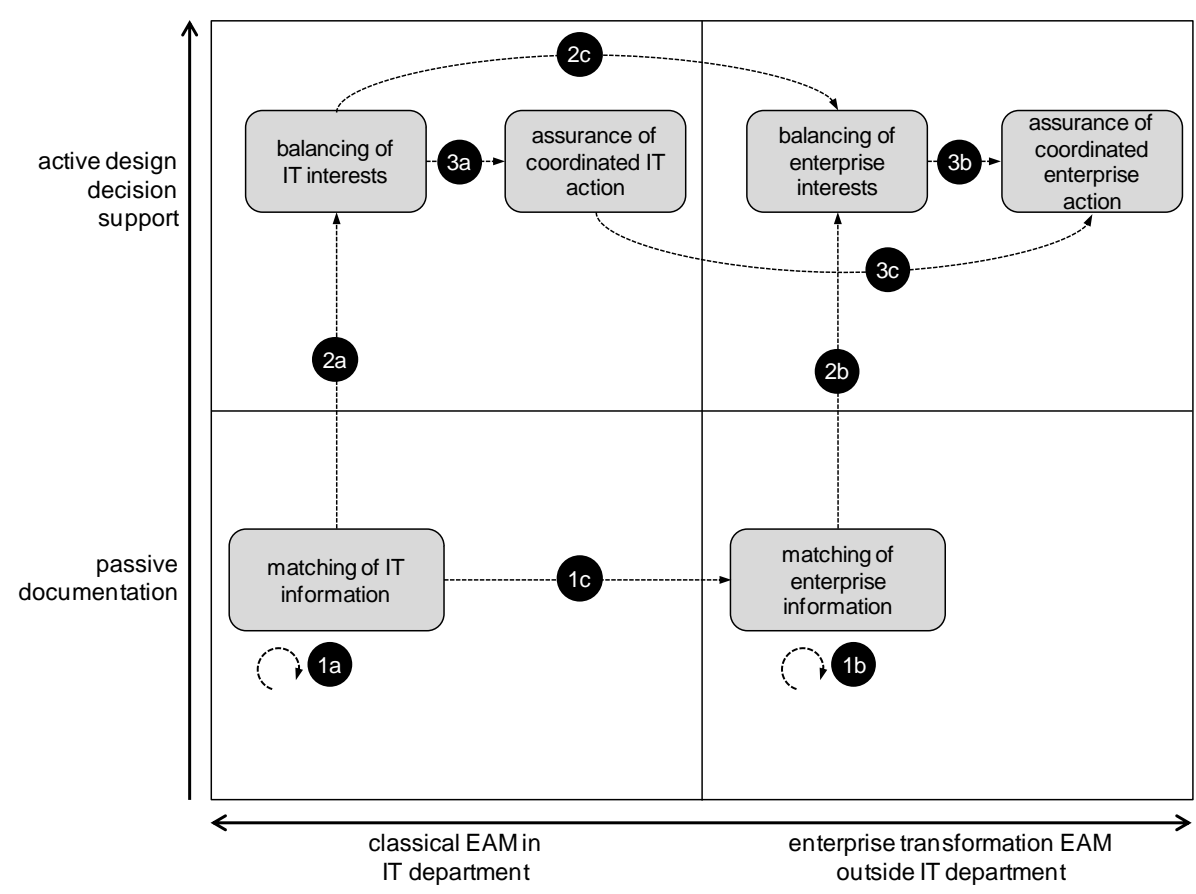

Fig. 3. Development paths of classical passive (IT-)EAM to an active enterprise transformation EAM

Dimension one, on the vertical axis, describes the way EAM influences an enterprise - in a passive, documentation-oriented way or in a way of active design and decision support. Dimension two on the horizontal axis describes the scope and therefore the positioning of EAM-being either an IT-focused approach (typically positioned within the IT department) or being an enterprise-wide function positioned outside IT.

EAM may evolve from its historical starting point (step 1a) as an IT-rooted, passive documentation approach along these two dimensions on two evolution paths: (1) 
becoming an active design decision support in the IT domain (step 2a), then taking its services out of the IT department to an enterprise-level (steps $2 \mathrm{c}$ or $3 \mathrm{a}$ and $3 \mathrm{c}$ ), or (2) first take the step out of the IT department (step 1c) and then moving from a documentation role to a design decision support discipline (steps $2 \mathrm{~b}$ or $2 \mathrm{~b}$ and $3 \mathrm{~b}$ ). A direct leap from classical IT-driven EAM in a passive, documentation-centered role (lowerleft quadrant) to an active decision-support function with enterprise-wide focus (upper-right quadrant) would be a radical step that is unlikely to be taken directly. Instead, enterprises can build on their experiences of applying EAM to the IT domain when extending EAM to an enterprise-wide function [27].

If EAM keeps its classical role in the IT department, it can only coordinate in an IT context. In its reactive role, it may provide information support in matching games (step 1a). If it evolves into a design support discipline for IT issues, it may help balance in a battle of the sexes game, e.g. between developers and maintenance personnel (step 2a), or help establish mutual trust in an assurance game, e.g. between different development teams (step 3a).

If EAM is to support enterprise-wide coordination, the coordination games it supports are much wider in scope: instead of balancing local interests or building trust between players from one single domain as in the IT context, EAM takes an enterprise-wide scope. The games it supports are played between players from different domains across the enterprise. They include battle of the sexes games such as balancing between business-specific requirements and IT standardization goals described as "managed evolution" by Murer et al. [32] or as business/IT alignment by others [39, $40,41]$. Even more challenging are enterprise-wide assurance games of building convergent expectations and mutual trust between business, IT and corporate functions. In order to provide these services, EAM has to move out of the IT department and take one of the paths envisioned for instance by Gartner [10]: Become a corporate decision support discipline, or merge its products and processes into business strategy. In the latter case, EAM may evolve along path 1c, merging its information supply capabilities into other strategic disciplines that eventually provide active design decision support.

Independent of which development path EAM eventually takes, key requirements for enterprise-wide coordination games can only be fulfilled if EAM (1) manages to provide transparency and (2) is perceived as a corporate discipline. Visibility to stakeholders and providing organizational history from a credible, domainindependent perspective cannot be achieved if EAM is perceived as covering only a domain-specific viewpoint instead of having an enterprise-wide scope.

From our analysis of coordination games in enterprises, two main propositions for EAM may be derived:

P1a: EAM successfully supporting the matching game is a precondition for EAM successfully supporting the battle of the sexes game.

P1b: EAM successfully supporting the battle of the sexes game is a precondition for EAM successfully supporting the assurance game.

P2: In order for EAM to generate impact outside the IT domain, EAM has to be positioned outside the IT department. 
Proposition P1 may be intuitive because it conforms to the experiences in maturing EAM or other coordination functions. Proposition P2, however, seems more interesting since it can be observed in practice, that enterprise architects constantly struggle with their role, tasks, and success outside their domestic IT department. While trying to better understand the requirements and also the habits of their business stakeholders is a necessary task, the emancipation from their "IT birthplace" may only be observed in very few places, yet.

\section{Summary}

\subsection{Limitations}

The results of this paper must be interpreted considering a number of limitations: First, game theory makes strong assumptions that include rational players and information asymmetry. Therefore, the applicability of game theory to real-life situations heavily depends on the degree to which these assumptions actually hold.

Moreover, in order to limit complexity, we have focused on 2-player games in this paper. However, repeatedly played games with more than two players (n-player games) can provide a more realistic yet considerably more complex description of organizational conflicts.

Additionally, many types of organizational coordination situations could involve elements of several of the games discussed herein, or may not be covered fully by the games discussed (e.g., to which extent does a pure battle of the sexes game exist in a real-world enterprise with a plethora of stakeholders and their inter-linked interests).

These limitations will particularly come forward during validation, i.e. when mapping concrete organizational situations to one of the games discussed in this paper and applying the EAM design implications. Nevertheless, applying game theory in a simplified form does provide a first classification scheme of organizational coordination situations. However, it needs to be considered that the true complexity of real-life organizations can at best be approximated by two-by-two payoff matrices.

\subsection{Conclusion}

In this paper, we have taken a game-theoretic look on coordination situations in enterprises and derived design implications for EAM from three coordination games. The major findings are that (1) transparency and visibility of EAM information to stakeholders are a key requirement in all coordination games, that (2) EAM must pass a maturing cycle, with rising requirements from supporting matching game situations to supporting coordination in the assurance game, and that (3) in order to support enterprise transformation, i.e. transformation cutting across single domains, EAM should be positioned as an enterprise-level support function outside the IT departments, in order to increase its visibility.

Further research should look into more specific coordination and transformation situations (like Mergers \& Acquisitions, the launch of new products or regulatory 
changes mandating changes in information systems) and more specific EAM deliverables such as certain types of models (e.g., on dependencies, decision rationales, goals) or principles (e.g., on different levels of granularity). The role of EAM in coordinating such transformation efforts could be analyzed in case studies. The propositions derived in the previous section may thus be tested for validity, reliability and generalizability.

The current work provides as its main contribution a theoretically founded set of propositions and evolution paths for EAM in the course of enterprise transformation.

\section{Acknowledgement}

This work has been supported by the Swiss National Science Foundation (SNSF).

\section{References}

1. Rouse, W.B.: A Theory of Enterprise Transformation. Systems Engineering 8:4, 279--295 (2005)

2. Purchase, V., Parry, G., Valerdi, R., Nightingale, D., Mills, J.: Enterprise Transformation: Why Are We Interested, What Is It, and What Are the Challenges? Journal of Enterprise Transformation 1:1, 14--33 (2011)

3. Rouse, W.B.: Enterprises as systems: Essential challenges and approaches to transformation. Systems Engineering 8:2, 138--150 (2005)

4. Harmsen, F., Proper, E., Kok, N.: Informed Governance of Enterprise Transformations. In: Proper, E., Harmsen, F., Dietz, J.L.G. (eds.): Advances in Enterprise Engineering II, pp. 155--180. Springer, Berlin Heidelberg (2009)

5. Pulkkinen, M., Naumenko, A., Luostarinen, K.: Managing information security in a business network of machinery maintenance services business - Enterprise architecture as a coordination tool. Journal Of Systems And Software 80:10, 1607--1620 (2007)

6. Ross, J.W., Weill, P., Robertson, D.C.: Enterprise Architecture as Strategy. Creating a Foundation for Business Execution. Harvard Business School Press, Boston, MA (2006)

7. The Open Group: TOGAF Version 9.1 (2011)

8. Proper, E., Greefhorst, D.: The Roles of Principles in Enterprise Architecture. In: 5th International Workshop on Trends in Enterprise Architecture Research (TEAR 2010), pp. 57--70. Springer, Delft (2010)

9. Aier, S., Gleichauf, B., Winter, R.: Understanding Enterprise Architecture Management Design - An Empirical Analysis. In: Proceedings of the 10th International Conference on Wirtschaftsinformatik WI 2.011, pp. 645--654, Zurich (2011)

10. Gartner Inc.: The Future of EA in 2020; EA Is Integral to Strategic Planning. (2011)

11. Lucke, C., Krell, S., Lechner, U.: Critical Issues in Enterprise Architecting - A Literature Review. In: AMCIS 2010 Proceedings. Paper 305. (2010)

12. Aumann, R.J.: What is game theory trying to accomplish? In: Arrow, K., Honkapohja, S. (eds.): Frontiers of Economics, pp. (1985)

13. Weber, R., Camerer, C., Rottenstreich, Y., Knez, M.: The Illusion of Leadership: Misattribution of Cause in Coordination Games. Organization Science 12:5, 582--598 (2001) 
14. Camerer, C., Knez, M.: Coordination in organizations: A game-theoretic perspective. In: Shapira, Z. (ed.): Organizational decision making, pp. 158--188. Cambridge University Press, New York (1997)

15. Rabin, M.: Incorporating Fairness into Game Theory and Economics. The American Economic Review 83:5, 1281--1302 (1993)

16. Marschak, J., Radner, R.: Economic Thoery Of Teams. Yale University Press, New Haven and London (1972)

17. Camerer, C., Knez, M.: Coordination, Organizational Boundaries and Fads in Business Practices. Industrial and Corporate Change 5:1, 89--112 (1996)

18. Fischer, C., Winter, R., Aier, S.: What is an Enterprise Architecture Design Principle? Towards a Consolidated Definition. In: Lee, R. (ed.): Computer and Information Science 2010, pp. 193--205. Springer, Berlin, Heidelberg (2010)

19. Stelzer, D.: Enterprise Architecture Principles: Literature Review and Research Directions. In: Service-Oriented Computing. ICSOC/ServiceWave 2009 International Workshops, Stockholm, Sweden, November 23-27, 2009, Revised Selected Papers, pp. 12--21. Springer, Stockholm (2010)

20. ISO/IEC/IEEE: Systems and software engineering -- Architecture description (ISO/IEC/IEEE 42010:2011). Springer, Heidelberg (2011)

21. Spewak, S.H., Hill, S.C.: Enterprise Architecture Planning - Developing a Blueprint for Data, Applications and Technology. John Wiley \& Sons, New York (1993)

22. Spewak, S.H., Tiemann, M.: Updating the Enterprise Architecture Planning Model. Journal Of Enterprise Architecture 2:2, 11--19 (2006)

23. Pulkkinen, M.: Systemic Management of Architectural Decisions in Enterprise Architecture Planning. Four Dimensions and Three Abstraction Levels. In: Proceedings of the 39th Annual Hawaii International Conference on System Sciences (HICSS 2006), pp. 179a (171-179). IEEE Computer Society, Honolulu, Hawaii (2006)

24. Jonkers, H., Lankhorst, M., Doest, H.W.L., Arbab, F., Bosma, H., Wieringa, R.J.: Enterprise architecture: Management tool and blueprint for the organisation. Information Systems Frontiers 8:enterprise architecture, 63--66 (2006)

25. Lankhorst, M.: Enterprise Architecture at Work: Modelling, Communication and Analysis. Springer, Berlin et al. (2005)

26. Strano, C., Rehmani, Q.: The Role of the Enterprise Architect. International Journal of Information Systems and e-Business Management 5:4, 379--396 (2007)

27. Radeke, F.: Toward Understanding Enterprise Architecture Management's Role in Strategic Change: Antecedents, Processes, Outcomes. In: Wirtschaftinformatik Proceedings 2011. Paper 62. (2011)

28. Winter, R., Bucher, T., Fischer, R., Kurpjuweit, S.: Analysis and Application Scenarios of Enterprise Architecture - An Exploratory Study (Reprint). Journal Of Enterprise Architecture 3:3, 33--43 (2007)

29. Niemi, E.: Enterprise Architecture Stakeholders - A holistic view. In: The 13th Americas Conference on Information Systems (AMCIS 2007), Keystone, CO (2007)

30. Pries-Heje, J., Baskerville, R.L.: The Design Theory Nexus. MIS Quarterly 32:4, 731--755 (2008)

31. Boh, W.F., Yellin, D.: Using Enterprise Architecture Standards in Managing Information Technology. Journal Of Management Information Systems 23:3, 163--207 (2007)

32. Murer, S., Bonati, B., Furrer, F.J.: Managed Evolution: A Strategy for Very Large Information Systems. Springer, Heidelberg (2010) 
33. Brunninge, O.: Using history in organizations: How managers make purposeful reference to history in strategy processes. Journal of Organizational Change Management 22:1, 8--26 (2009)

34. Aveiro, D., Silva, A.R., Tribolet, J.: Towards a G.O.D. Organization for Organizational Self-Awareness. In: Albani, A., Dietz, J.L.G. (eds.): Advances in Enterprise Engineering IV, pp. 16--30. Springer, Berlin Heidelberg (2010)

35. Kluge, C., Dietzsch, A., Rosemann, M.: How to realise corporate value from enterprise architecture. In: ECIS 2006 Proceedings. Paper 133. (2006)

36. Asfaw, T., Bada, A., Allario, F.: Enablers and Challenges in Using Enterprise Architecture Concepts to Drive Transformation: Perspectives from Private Organizations and Federal Government Agencies. Journal Of Enterprise Architecture 5:3, 18--28 (2009)

37. Brown, A.E., Grant, G.G.: Framing the Frameworks: A Review of IT Governance Research. Communications Of The Association For Information Systems 15:May, 696--712 (2005)

38. Pirson, M., Malhotra, D.: Foundations of Organizational Trust: What Matters to Different Stakeholders? Organization Science 22:4, 1087--1104 (2011)

39. Henderson, J.C., Venkatraman, N.: Strategic alignment: Leveraging information technology for transforming organizations. IBM Systems Journal 32:1, 4--16 (1993)

40. Aier, S., Winter, R.: Virtual Decoupling for IT/Business Alignment - Conceptual Foundations, Architecture Design and Implementation Example. Business \& Information Systems Engineering 1:2, 150--163 (2009)

41. Chan, Y.E., Reich, B.H.: IT alignment: an annotated bibliography. Journal Of Information Technology 22:4, 316--396 (2007) 